\title{
Maternal and perinatal morbidity and mortality in COVID-19 positive obstetrics patients in tertiary care centre
}

\author{
Medha $^{1}$, Neeta Chaudhary ${ }^{1 *}$, Smita Tyagi ${ }^{1}$, Kirtigiri G. Goswami ${ }^{2}$
}

\begin{abstract}
${ }^{1}$ Department of Obstetrics and Gynaecology, ${ }^{2}$ Chief Medical Superintendent, Muzaffarnagar Medical College, Muzaffarnafar, Uttar Pradesh, India
\end{abstract}

Received: 14 February 2021

Revised: 12 June 2021

Accepted: 14June 2021

\section{*Correspondence:}

Dr. Neeta Chaudhary,

E-mail: drneetachaudhary1261@gmail.com

Copyright: (c) the author(s), publisher and licensee Medip Academy. This is an open-access article distributed under the terms of the Creative Commons Attribution Non-Commercial License, which permits unrestricted non-commercial use, distribution, and reproduction in any medium, provided the original work is properly cited.

\begin{abstract}
Background: COVID-19 disease had been declared as a public health crisis by WHO by the end of 2019 . The effect of SARS-CoV-2 infection on pregnancy including symptoms, disease severity, risk of vertical transmission and perinatal and neonatal outcome have been the subject of research. Preliminary studies showed a fluctuating course of the disease ranging from asymptomatic or mild symptoms to even maternal death. However, recent evidences suggest that effect of COVID-19 infection during pregnancy may not lead to adverse maternal and neonatal outcome.

Methods: In this cross sectional prospective observational study, we analysed 60 pregnant women infected with SARSCoV-2 and their neonatal outcome, who tested positive for COVID-19 at district hospital, and were referred to Muzaffarnagar Medical College, were enrolled in this study.

Results: The majority $96.7 \%$ (58) of these women were asymptomatic with cough being the most common symptom which was present in $3.3 \%$ (2) of the women. 24(75\%) women developed pneumonitis radiologically, but they were asymptomatic, so intensive care was not required. Along with 76.08\% (35) perinatal/neonatal outcomes were observed normal.

Conclusions: In this study we observed that most of the women with COVID-19 were asymptomatic or with mild symptoms. Even though they were asymptomatic, most of the patients showed pneumonitis changes radiologically but still they didn't require any intensive care, had good recovery postpartum and were discharged under satisfactory condition. The neonatal outcome was highly favourable.
\end{abstract}

Keywords: SARS-Cov 2, COVID-19, Pregnant women, Neonate

\section{INTRODUCTION}

A novel coronavirus first emerged in Wuhan, China, in late December of 2019 and rapidly spread to become a global pandemic, later named severe acute respiratory syndrome coronavirus 2 (SARS-CoV-2), causing an illness known as covid-19. ${ }^{1}$ The World Health Organization has declared it as a public health crisis. A global estimate of 10,094,801 human infections, 146,414 deaths, 9,656,883 recovered cases reported worldwide as of December 22, 2020. Coronavirus, belongs to the family Coronaviridae.
Coronaviruses have enveloped virions and contains a single strand of positive sense RNA (ribonucleic acid). it has crownlike, or coronal, appearance due to presence of Club-shaped glycoprotein spikes in the envelope. COVID19 is highly contagious disease. Respiratory droplets and direct contact is the main route of transmission. It infects both the upper and lower respiratory tract and can cause pneumonia. Spectrum of the diseases range from asymptomatic to symptoms like fever, cough, muscle aches, vomiting, diarrhoea, nasal congestion, loss of taste and smell sensation and can progress to shortness of breath 
and complications from pneumonia. It also infects pregnant women but the majority of patient's experience only mild or moderate symptoms than other healthy adults. $^{2}$ Recent evidence from the UK also suggests that COVID-19 positive pregnant women are at no greater risk of developing serious disease. ${ }^{3}$ Pregnant women who are elderly, overweight, and have pre-existing medical conditions such as hypertension and diabetes, heart disease (congenital or acquired) are at increased risk of developing severe disease. Current evidence suggests that risk of vertical transmission (transmission from a mother to fetus antenatally or intrapartum) is very low or absent. ${ }^{4}$ If it does occur, it appears to not be affected by mode of birth, method of feeding or whether the woman and baby stay together (rooming in). ${ }^{5}$ There has been no significant increase in the incidence of congenital abnormalities reported till date. It has been shown that an approximately three-fold increased risk of preterm birth and also associated with an increased rate of caesarean birth.

\section{METHODS}

This was a cross sectional prospective observational study, conducted at Gynae and Obstetric Department, Muzaffarnagar Medical College (MMCH), between July 2020 to January 2021. Statistical Analysis was performed with help of Epi Info (TM) 7.2.2.2 EPI INFO is a trademark of the Centres for Disease Control and Prevention (CDC). Descriptive statistical analysis was performed to calculate the means with corresponding standard deviations (S.D.). Test of proportion was used to find the Standard Normal Deviate $(\mathrm{Z})$ to compare the difference proportions. $\mathrm{p}<0.05$ was taken to be statistically significant. Sixty pregnant women, tested positive for COVID-19 at district hospital, regardless of symptoms or gestational age were referred to our institute for at least 14 days for isolation or for resolution of symptoms, and were enrolled in this study. Both labour andnon-labour patients were included in the study. On admission, all routine antenatal testing, Ultrasonography (USG), corona specific testing includes Interleukin-6 (IL-6), C-reactive protein (CRP), D-Dimer and serum ferritin were done. Fetal surveillance was done by modified biophysical profile Non-Stress Test (NST)and Amniotic fluid index (AFI) and subjects were followed -up till delivery. All the recommended guidelines as directed by MoHFW regarding requisite measures including PPE Kits, Gloves, KN-95 masks, goggles and face shields were taken care of in the ward, labour room and operation theatre.

\section{Inclusion criteria}

Nasopharyngeal and pharyngeal swabs of the COVID-19 positive pregnant women were taken for sampling with confirmatory diagnosis done with the aid of real-time reverse transcriptase-polymerase chain reaction (RTPCR) or True Nat method of testing were included for the study.

\section{Exclusion criteria}

Pregnant women presenting signs and symptoms similar to that of COVID-19, yet testing negative for RT-PCR/True Nat were excluded.

\section{RESULTS}

A study was performed over 60 COVID-19 positive pregnant women. The mean age was 27.3 (20-36) years with $63.3 \%$ cases $<30$ years and 26.7 cases were $>30$ years. $51.7 \%$ (31) cases were unbooked while $48.3 \%$ (29) were booked.

Table 1: Demographic Characteristics of the studied subjects.

\begin{tabular}{|lc|}
\hline $\begin{array}{l}\text { Clinical } \\
\text { characteristics }\end{array}$ & $\begin{array}{l}\text { Number of patients } \\
(\%)\end{array}$ \\
\hline Age group (years) & $20(33.3 \%)$ \\
\hline $20-24$ & $24(40 \%)$ \\
\hline $25-29$ & $11(18.3 \%)$ \\
\hline $30-34$ & $5(8.4 \%)$ \\
\hline $35-39$ & $29(48.3 \%)$ \\
\hline Booking status & $31(51.7 \%)$ \\
\hline Booked & $57(95 \%)$ \\
\hline Un-booked & $2(3.3 \%)$ \\
\hline Obstetrics status on admission \\
\hline Antenatal & $1(1.7 \%)$ \\
\hline Postnatal & $19(32.2 \%)$ \\
\hline Abortion & $40(67.8 \%)$ \\
\hline Gestational Age of patient on admission \\
\hline$<37$ & $21(35 \%)$ \\
\hline$\geq 37$ & $39(65 \%)$ \\
\hline Gravidity & $58(96.7 \%)$ \\
\hline Primigravida & $2(3.3 \%)$ \\
\hline Multigravida & \\
\hline COVID-19 Symptoms & \\
\hline Asymptomatic & \\
\hline Cough & \\
\hline
\end{tabular}

Majority $96.7 \%$ (58) of the cases were asymptomatic, symptomatic cases with cough were $3.3 \%$ (2). On the basis of our data, 95\% (57) of the cases were Antenatal, while Postnatal and Abortion were $3.3 \%$ (2) and $1.7 \%$ (1) respectively.

Note: Postnatal cases admitted in the hospital were referred after the delivery outside the hospital. Of the total Antenatal cases $32.3 \%$ (19) were $<37$ weeks, while $67.8 \%$

(40) were $>37$ weeks POG. Of all the cases observed, Multigravida and Primigravida were 65\% (39) and 35\% (21) respectively. 
Of all the cases NVD and conservative management was given to $15.2 \%$ (7) and $21.67 \%$ (13) respectively while $1.66 \%$ (1) being Incomplete first trimester Abortion, majority $65 \%$ (39) being LSCS. Complications such as fetal distress $35.89 \%$ (14), scar tenderness $23.07 \%$ (9), preeclampsia $15.39 \%$ (6), post-dated pregnancy $10.25 \%$ (4), previous 2LSCS with pain abdomen $7.69 \%$ (3), oligohydramnios $5.12 \%$ (2), malpresentation (transverse lie) $2.56 \%(1)$.

Table 2: Mode of delivery.

\begin{tabular}{|l|l|}
\hline LSCS & $39(\mathbf{8 4 . 8 \% )}$ \\
\hline NVD & $7(15.2 \%)$ \\
\hline Indication for LSCS & \\
\hline Fetal distress & $14(40 \%)$ \\
\hline Scar tenderness & $9(26 \%)$ \\
\hline Pre-eclampsia & $6(17 \%)$ \\
\hline Postdated pregnancy & $3(8 \%)$ \\
\hline Previous 2LSCS with pain abdomen & $1(3 \%)$ \\
\hline Oligohydramnios & $1(3 \%)$ \\
\hline Malpresentation (Transverse lie) & $1(3 \%)$ \\
\hline
\end{tabular}

Table 3: Treatment provided to the patient.

\begin{tabular}{|l|l|}
\hline Antibiotic & $\mathbf{6 0}(\mathbf{1 0 0 \% )})$ \\
\hline Hydroxychloroquine (HCQ) & $35(58.3 \%)$ \\
\hline Antiviral treatment & $25(41.7 \%)$ \\
\hline Use of steroids & $25(41.7 \%)$ \\
\hline Conservative management only & $13(21.7 \%)$ \\
\hline ICU admission & $2(3.3 \%)$ \\
\hline
\end{tabular}

Table 4: Laboratory findings.

\begin{tabular}{|lc|}
\hline C-Reactive protein normal range: & $<\mathbf{5}$ mg/L \\
\hline CRP raised & $48(80 \%)$ \\
\hline CRP normal & $12(20 \%)$ \\
\hline Interleukins 6 & Normal range: $\mathbf{1 . 8} \mathbf{~ p g / m l ~ ( 1 3 ~ c a s e s ) ~}$ \\
\hline IL-6 range & $13(21.6 \%)$ \\
\hline Chest X-Ray findings (32 cases) & \\
\hline Pneumonitis & $24(75 \%)$ \\
\hline Normal & $8(25 \%)$ \\
\hline
\end{tabular}

All pregnant postpartum women were administered antibiotics and enoxaparin. 58.3\% (35) were given HCQ, $41.7 \%$ (25) were given Antiviral drugs, $41.7 \%$ (25) were given Steroids. Injection methyl-prednisolone and tablet hydroxychloroquine $400 \mathrm{mg} 12$ hourly loading dose on day 1 followed by $200 \mathrm{mg} 12$ hourly for next 4 days and improvement in symptoms were noted. Vitamin $\mathrm{C}$ and zinc were also given to all patients. Antiviral Remedesivir was given postpartum. $21.7 \% \quad$ (13) were managed conservatively and only $3.3 \%$ (2) were ICU admissions.
Appreciable number of pregnant women $80 \%$ (48) had heightened CRP levels, while 13 pregnant women upon whom IL6 was performed had abnormal levels of IL6. Patients were shifted to oxygen bed and oxygen saturation (SpO2) was monitored. On chest x-ray examination of 32 pregnant women, $75 \%$ (24) presented with pneumonitis, while normal findings were found in $25 \%$ (8) women.

Relatively lower number of deaths were observed during treatment $3.3 \%$ (2) when compared to $96.7 \%$ (58) that were discharged after treatment in good condition. Along with $76.08 \%$

(35) perinatal/neonatal outcomes were observed normal. NICU admission $6.52 \%$ (3) was higher than preterm neonates $2.17 \%$ (1) and neonatal deaths $2.17 \%$ (1). Proportion of IUGR being at $8.69 \%$ (4) which was higher than IUDs observed $4.34 \%$ (2).

Table 5: Clinical outcomes of the studied subjects.

\begin{tabular}{|c|c|}
\hline \multicolumn{2}{|c|}{$\begin{array}{l}\text { Maternal and perinatal / neonatal morbidity an } \\
\text { mortality }\end{array}$} \\
\hline Normal & $35(76.08 \%)$ \\
\hline IUGR & $4(8.09 \%)$ \\
\hline NICU Admissions & $3(6.52 \%)$ \\
\hline IUD & $2(4.34 \%)$ \\
\hline Preterm & $1(2.17 \%)$ \\
\hline Neonatal death & $1(2.17 \%)$ \\
\hline \multicolumn{2}{|l|}{ Clinical outcome } \\
\hline Discharged & $58(96.7 \%)$ \\
\hline Deaths & $2(3.3 \%)$ \\
\hline
\end{tabular}

\section{DISCUSSION}

In this study of 60 cases of pregnant women with COVID19 infection diagnosed during routine antenatal check-up at district hospital, were referred to our college irrespective of the symptoms and gestational age. FOGSI guidelines also recommends COVID-19 testing should be performed in all the pregnant women even if asymptomatic, presenting in labour or likely to deliver in next 5 days. ${ }^{6}$ Out of these $60,96.7 \%$ (58) were asymptomatic and $3.3 \%$ (2) were symptomatic presenting with cough. Studies done by Muhidin et al also concluded that cough and fever were the most common symptoms in COVID 19 positive pregnant women. $^{7}$ In our study, the median gestational age on diagnosis was 37.64, and $32.2 \%$ (19) of the patients were $<37$ weeks POG and $67.8 \%$ (40) of the patients were $\geq 37$ weeks POG. Study conducted by Knight et al also had similar findings. ${ }^{8}$ On admission apart from routine antenatal testing, COVID-19 specific tests i.e., CRP and IL6 were sent. Due to the non-availability of IL-6 facility in our centre, IL6 testing was started later and was performed in only 13 cases where IL- 6 levels were found to be elevated in all the cases. Elevated C-reactive protein levels were found in $80.0 \%$ (48) cases. In pregnant women with COVID 19, the physiological "silencing" of the Th1 
pro- inflammatory response with the relative dominance of Th2 suppresses the inflammatory cascade as compared to non-pregnant subjects therefore hampering the severity of the disease and leading to lower incidence of maternal deaths. ${ }^{9}$ In our study also, despite of raised inflammatory markers, both, maternal and neonatal outcomes were favourable. In a study conducted by Yan et al showed that out of 116 cases, $65.5 \%$ (76) cases had been discharged with no maternal deaths. ${ }^{10}$ Similarly, in our study, we found favourable outcomes among pregnant women with covid19 infection with maternal mortality being only $3.3 \%$ (2). Post operatively on day 2 , two patients were admitted in ICU because of worsening of COVID-19 19 symptoms, both the patients died due to pulmonary embolism. As we know pregnancy is a hypercoagulable state, so monitoring of D-dimer is also necessary. ${ }^{11}$ A case series study has reported elevated D-dimer in pregnant women with COVID-19 and its association with increased mortality rate. ${ }^{12}$ In our study, $75 \%$ (24) had radiological diagnosis of pneumonia, out of which only 2 patients died due to worsening of respiratory conditions. A prospective cohort study conducted by

Knight et al also showed that out of 427 pregnant women with confirmed SARS-CoV-2 infection, 10\% women required respiratory support and $1 \%$ women died. ${ }^{8}$ Hence, it showed that despite having pneumonitis features radiologically, maternal mortality and morbidity rates were low. In our study, $84.8 \%$ (39) of neonates were delivered by caesarean section, indications being fetal distress, scar tenderness, pre-eclampsia, post-dated pregnancy, previous 2 LSCS, oligohydramnios and malpresentation. These findings are supported by the UKOSS study, where $59 \%$ of women had caesarean births; half of which were because of maternal or foetal compromise. Rest were because of obstetric reasons (example, progress in labour, previous caesarean birth) or maternal request (6\%). Out of 46 neonates, only $6.52 \%$ (3) were admitted in NICU, $2.17 \%$ (1) neonatal mortality occurred, $4.34 \%$ (2) intrauterine death occurred due to abruptio and aspiration pneumonitis (Thick Meconium stained liqour)

\section{Limitations}

We acknowledge the limitations of this review that a full and comprehensive search would have taken more time than was available. We used limited database in order to conduct this study.

\section{CONCLUSION}

In this study we observed that most of the women with COVID-19 were asymptomatic or with mild symptoms. Even though they were asymptomatic, most of the patients showed pneumonitic changes radiologically. Initially symptomatic treatment was started and enoxaparin was given along with antibiotic and antiviral agents. This aggressive treatment given to covid-19 obstetric patients led to less requirement of any intensive care, had good recovery postpartum and were discharged under satisfactory condition. Even the neonatal outcome was highly favourable. We think our study will be very helpful to carry this research further to combat and win the virus.

Funding: No funding sources

Conflict of interest: None declared

Ethical approval: The study was approved by the Institutional Ethics Committee

\section{REFERENCES}

1. World Health Organization. Novel coronavirus situation $\quad$ report-2. 2020. https://www.who.int/docs/defaultsource/coronaviruse/situation-reports/20200122sitrep-2-2019-ncov. Accessed on 14 January, 2021.

2. Public Health England. COVID-19: investigation and initial clinical management of possible cases 2020. https://www.gov.uk/government/publications/wuhan - novel-coronavirus-initialinvestigation-of-possiblecases/investigation-and-initial-clinical- managementof-possible-cases-of-wuhannovel-coronavirus-wncov-infection. Accessed on 14 January, 2021.

3. Docherty AB, Harrison EM, Green CA. Features of 20133 UK patients in hospital with covid-19 using the ISARIC WHO Clinical Characterization Protocol: prospective observational cohort study. BMJ 2020;369:m1985.

4. Rasmussen SA, Smulian JC, Lednicky JA, Wen TS, Jamieson DJ. Coronavirus Disease 2019 (COVID-19) and pregnancy: what obstetricians need to know. Am J Obstet Gynecol. 2020;222(5):415-26.

5. Walker KF, O'Donoghue K, Grace N. Maternal transmission of SARS-COV-2 to the neonate, and possible routes for such transmission: a systematic review and critical analysis. BJOG. 2020;127(11):1324-36.

6. Indian Council for Medical Research. COVID-19 testing. Accessed on 28 March, 2020.

7. Muhidin S, Behboodi Moghadam Z, Vizheh M. Analysis of maternal coronavirus infections and neonates born to mothers with 2019-nCoV; a systematic review. Arch Acad Emerg Med. 2020;8:e49.

8. Knight M, Bunch K, Vousden N, Morris E, Simpson $\mathrm{N}$, Gale C, et al. Characteristics and outcomes of pregnant women admitted to hospital with confirmed SARS-CoV-2 infection inUK: national populationbased cohort study. BMJ. 2020;369:m2107.

9. Ghia T, di Pasquoa E, Mekinianb A, Calzac L, Fruscaa T. Sars-CoV-2 in pregnancy: Why is it better than expected? Eur J Obstet Gynecol Reprod Biol. 2020;252:476-8.

10. Yan J, Guo J, Fan C, Juan J, Yu X, Li J, et al. Coronavirus disease 2019 (COVID-19) in pregnant women: a report based on 116 cases. Am J Obstetr Gynecol. 2020;223(1):111.e1-14

11. Bremme KA. Haemostatic changes in pregnancy. Best Pract Res Clin Haematol. 2003; 16:153-68. 
12. Lokken EM, Walker CL, Delaney S, Kachikis A, Kretzer NM, Erickson A. Clinical characteristics of 46 pregnant women with a SARS-CoV-2 infection in Washington state. Am J Obstetr Gynecol. 2020;223(6):911.e1-14.
Cite this article as: Medha, Chaudhary N, Tyagi S, Goswami KG. Maternal and perinatal morbidity and mortality in COVID-19 positive obstetrics patients in tertiary care centre. Int J Reprod Contracept Obstet Gynecol 2021;10:2676-80. 